\title{
The initial cold and freeze-thaw cycle test comparative analysis research
}

\author{
G .y. WANG ${ }^{1, a^{*}}$, Z. Cheng ${ }^{2, b}$, L. Wang ${ }^{3, c}$ and S. $X^{4} e^{4, d}$ \\ ${ }^{1}$ College of civil engineering, Shenyang jianzhu University, Liaoning Shenyang 110168 \\ b1171701899@qq.com, ${ }^{\mathrm{d}} 474030570 @ q q . c o m$
}

Keywords: the initial cold; freeze-thaw cycles; concrete beams; mechanical properties.

Abstract. After the effects of initial cold, take the strength changes of C30 and C50 concrete block and the result of beam test load, concrete strain, tensile reinforcement strain and deflection of the beam for analysis. The result showed that the trends of concrete C30 and C50 is consistent, which are decreased while the freezing time increased after the initial cold. And the beam reinforcement strain of C30 was less than C50, especially in the initial 90 days. Under the same load function, the flexural performance of the beam with C50 was higher than that of C30 beams in initial 90 days, but the two curves coincide after 120 days.

\section{Introduction}

With the increase of high-rise and super high-rise buildings, the winter construction is increasingly common while the project construction period increased. And the concrete soon began to enter the initial cold effect after the pouring completed. The bearing capacity of reinforced concrete members and structures under the initial cold effect has been gaining momentum. So the author took the experimental study for the bearing capacity of reinforced concrete beam, deflection, strain of steel and crack and other mechanical properties are analyzed in detail.

\section{The Test Result}

\section{Analyze the strength of concrete test block}

Pouring and curing concrete block for $150 \mathrm{~mm} \times 150 \mathrm{~mm} \times 150 \mathrm{~mm}$ for three specimens per group under standard conditions. Then take them out of the lab when the intensity values reach their intensity after indoor $\left(15^{\circ} \mathrm{C}\right)$ maintenance of a day and the initial cold of the corresponding time and natural conservation. The reinforced concrete beam is $1500 \mathrm{~mm} \times 100 \mathrm{~mm} \times 200 \mathrm{~mm}$, which composed

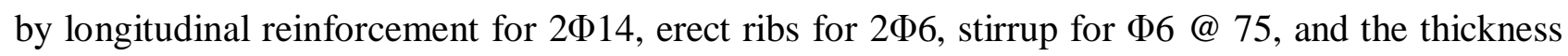
of the protective layer is $25 \mathrm{~mm}$. In order to facilitate loading, leaving the ends of each beam 100mm, and the calculation span is $1300 \mathrm{~mm}$.

Figure 1 shows the strength variation of $\mathrm{C} 30$ and $\mathrm{C} 50$ concrete test block in the early period after the cold. It does can be seen: the trends of C30 concrete strength is consistent to C50, both of them are decreased while the freezing time increased.

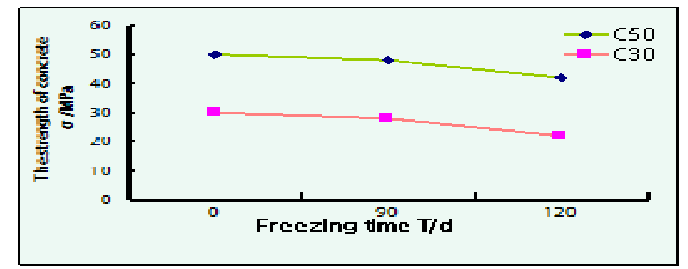

Fig. 1 Concrete block strength contrast 


\section{The experimental phenomena}

Figure 2 shows the beam's failure forms under load after the initial cold.
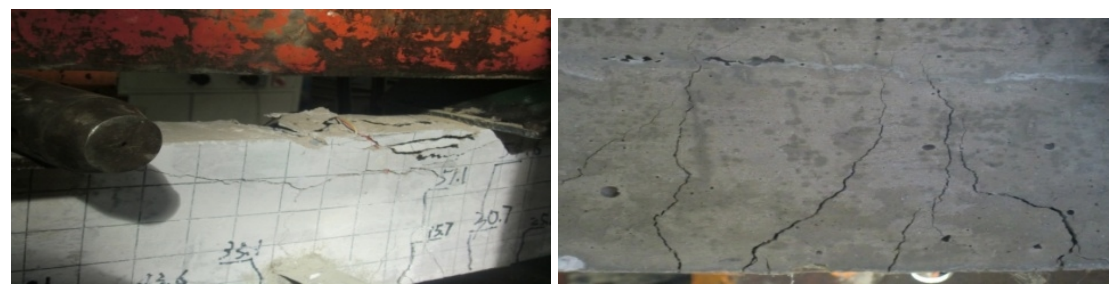

Crushed concrete in compression zonePure bending section fracture

Fig. 2Concrete crack of beam test

At the beginning of loading, the components are in elastic stage. The section is untracked because the bending moment by the load is small, and the performance of the beam characteristics of elastic deformation, the deflection and strain showed a linear change. When the load further increased but within yield load, Concrete C30 beam cracks appeared at first compared to concrete C50 beam, but the cracks develop slow. When the load value reached the limit, a large number of cracks appeared and width rapidly increased. And the concrete in the compression zone are crushed.

In the experiment, the first cracks of concrete C30 beams as well as C50 are vertical in the span position. However, when compared to $\mathrm{C} 50$ beam, the cracks of $\mathrm{C} 30$ beam appeared earlier and developed faster, the crushed concrete in compression zone is more serious and diagonal cracks appeared. While the C50 beams showed a crack on the side mostly are joints and the number of cracks which are vertical appear to be significantly greater than $\mathrm{C} 30$ beam.

The test load analysis

The test used the result of the cracking load, yield load and ultimate load of C30 and C50 beam as the bearing capacity, to analyze the changes of bearing capacity about the ordinary concrete and high strength concrete of reinforced concrete beams after initial freezing.

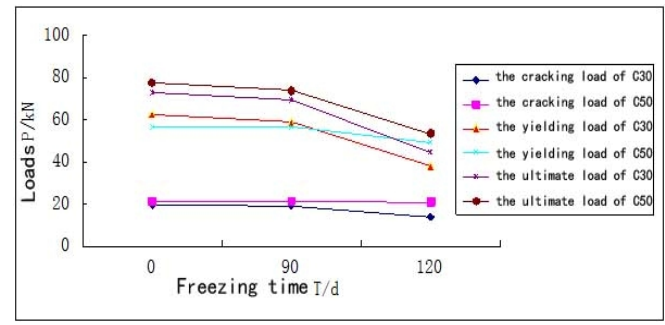

Fig. 3Contrast figure on beam bearing capacity of C30 and C50

From figure 3 can be found: The initial cold effect has a certain influence on bearing capacity of reinforced concrete beams, and the ultimate load is most prominent. Compared to C30 ordinary concrete beam, C50 high strength concrete beams in cracking load unchanged, that means there is no impact on the role of cold to the cracking load. However, the yield load of beam C50 is less than that of $\mathrm{C} 30$ on the condition of normal conservation and initial cold 90 days .Instead, the beam's yield load is greater than C30 after 120 days of initial cold. This illustrates the influence on yield load about initial freezing time on C30 is greater than C50.But the ultimate load value in initial cold 120 days is significantly lower than that of 90 days and the two folding lines are basically parallel, namely the change of both is basicaally the same. 


\section{The Test Analysis}

\section{Strain of Concrete}

From figure 4 can be clearly drawn: The stress in middle section of the beam on C30 is greater than C50's in either load. Because of the intensity values are not the same, so the compression zone of C30 reinforced concrete beams to be significantly higher than the C50.The stress value of C50 concrete beam is almost negligible in the initial 90 days of freezing effect, but it increased in the initial 120 days of freezing effect. This is mainly due to the concrete strength is lowered to cause the neutral axis moves up, and eventually lead to concrete strain values increase . It can determine that $\mathrm{C} 30$ concrete commitment to the stress values more and it is also explains the situation that the crack damage is more obvious, and more serious damage crushed to the compression zone.

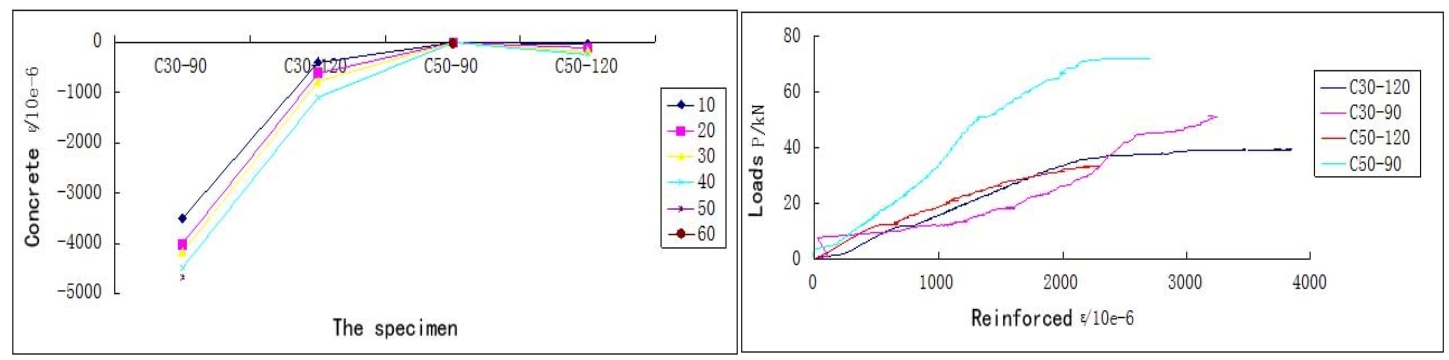

Fig. 4Maximum compressive strain curves of

Fig. 5 Strain curve of the steel mid-span section concrete

Tensile reinforcement strain analysis

Reinforced concrete structures or structures mainly take advantage of steel tensile strength to achieve better bending performance. Since the tensile strength of concrete in reinforced concrete beams are general neglected in the calculation of bending, the tensile stress are borne by the steel. So testing strain study on reinforcement is an important part of research of reinforced concrete structures

From figure 5 can be found: In terms of development trends, span steel beams strain values of C30 and C50 showed an increasing trend, but with small differences. Strain values of C30 steel beam were less than that of C50, and especially in the initial cold for 90 days prominent most. Combined with the figure 4, almost all steels bear the stress; the main reason is the change of the neutral axis location and the changes to its carrying capacity allocation after cracks. Therefore, in order to compensate the redistribution of stress caused by concrete cracking or neutral axis shift, we must fully consider the steel usage of high strength concrete elements or structures in the initial cold effect in the design and construction

\section{Deflection Analysis}

The deflection is an important index to measure the overall performance of reinforced concrete beams. The large deflection would affect the comfort and usability of the component or structure, the deflection is also a index to measure the stiffness of beam, as well as one of the conditions to judge whether the beam is damaged or not . 


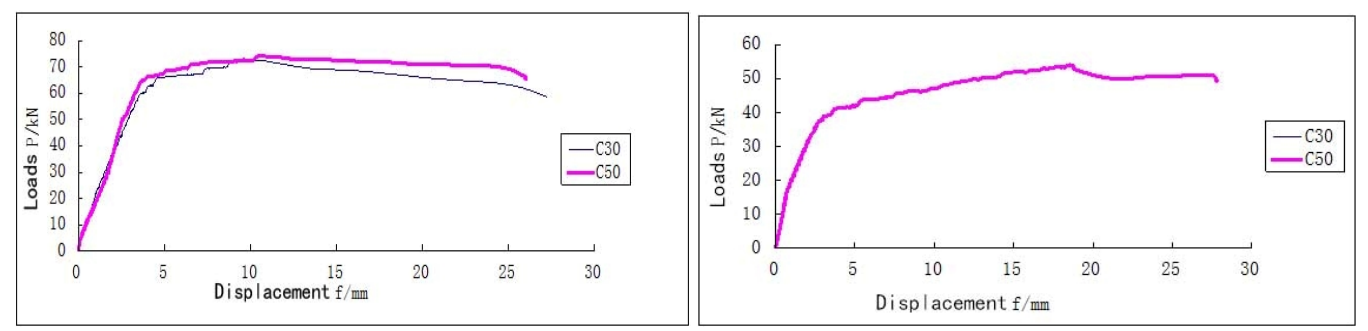

Beam load deflection curve in cold for 90days Beam load deflection curve inoldfor120 days

From figure 6 can be found: Under the same loads, the bending strength of reinforced concrete beam C50 is higher than that of C30 in the initial cold effect of 90 days. However, the two curves overlaps after the initial cold effect for 120 day, that is to say the bending strength of two beams are basically identical.

\section{Compared to Freeze-thaw cycles}

\section{Size effect}

Chana $^{[1]}$ selected the prototype for the cross-sectional dimensions $200 \mathrm{~mm} \times 400 \mathrm{~mm}$, and take model to testing with the method to reduce the proportion of these models for $1: 2 、 1: 3.3$. The results show that the size effect of the reinforced concrete beam has no influence to the bearing capacity of bending strength. This is because the bending failure of the beam mainly caused by the yield of tensile of longitudinal reinforcement. In addition, the main factors influencing the size effect is the concrete strength and the bond of concrete and steel. Therefore, the size effects only have a significant impact on the bearing performance of components or structures that the concrete compression strength reaches the limit value.

Through the conclusion above: We can ignore the effects of the bending mechanical properties of concrete simply-supported beam caused by the size effect.

\section{Concrete degeneration contrast}

Through this experimental study we can know that the strength of concrete would have the appropriate degree of decreased after the initial cold effect, and it related with the freezing time. A large number of experimental studies have shown that [3-5] the strength of concrete also degenerated after the freeze-thaw cycle, and put forward the corresponding calculation formula with freeze-thaw cycles as a parameter according to the test results.

Yang Zhongwei ${ }^{[2]}$ toke freeze-thaw cycle test with different times for standards cube concrete test block of C20, C30,C40 and C50 four levels and prisms test block for $100 \mathrm{~mm} \times 100 \mathrm{~mm} \times$ $300 \mathrm{~mm}$. Toke ordinary concrete for freeze-thaw cycles for 0,25,50,75,100 times, and high strength concrete for $0,25,50,75,100,125$ times. Then the concrete stress - strain curve equation and determine the parameters of the formula as follows.

$$
\begin{aligned}
& f_{d, c} / f_{c}=a+b n \\
& a=0.9981-0.00014 f_{c} \\
& b=-0.00916+0.000131 f_{c}
\end{aligned}
$$


Type 1 and 2 are applicable to calculate the intensity values of C30 ordinary concrete and C50 high strength concrete after the freeze-thaw cycles.

Wei Yan chao ${ }^{[3]}$ summarized the data in literature [41-43], in a way to take regression analysis, finally draws the relation between the compressive strength of ordinary concrete and freeze-thaw cycles for:

$$
\begin{aligned}
& \frac{f_{N}}{f_{c}}=1-\theta n \\
& \theta=0.0191-0.0004 f_{c}
\end{aligned}
$$

In the formula:

$f_{N}$ Isthe compressive strength of ordinaryconcrete after freeze-thaw cycles.

$f_{c}$ Is the compressive strength of ordinaryconcretewithout freeze-thaw cycles.

$\theta$ Is a coefficient related to the compressive stre- ngth of normal concrete without freeze-thaw.

Zhu Jinpeng ${ }^{[4]}$ made 24 C50 concrete blocks for $100 \mathrm{~mm} \times 100 \mathrm{~mm} \times 100 \mathrm{~mm}$. Then take themethod of freeze-thaw test and concrete meso mechanics numerical simulation analysis, and using least squares fitting for the ultimate compressive strength value after 100, 200, 300 times of freeze-thaw cycle, got the compressive strength reduction equations which relates to the parameter freeze-thaw cycles.

$$
f_{c}=f_{0} e^{-0.002 N}
$$

According to the calculation formula above proposed in the literature, the intensity values of concrete C30 and C50 after initial cold and freeze-thaw cycle effect were compared and analyzed. And the concrete C30 calculations were 0,25,50,75,100 times freeze-thaw cycles, the concrete C50 calculations were $0,25,50,75,100,125$ times.

The values of the strength concrete obtained by the contrasted test block in this experiment are used to analyze the experimental data, a specific comparison in table 1 to table 3 . 
Table 1 The testing concrete strength value

\begin{tabular}{ccc}
\hline & \multicolumn{2}{c}{ the Freezing time(T/d) } \\
Thestrength of concrete( $\sigma / \mathrm{Pa})$ & 90 & 120 \\
\hline C30 & 30.05 & 22.71 \\
C50 & 50.35 & 43.42 \\
\hline
\end{tabular}

Table 2 Comparison of concrete strength calculation on C30

\begin{tabular}{ccc}
\hline $\begin{array}{l}\text { The freeze-thaw } \\
\text { cycle times }\end{array}$ & \multicolumn{2}{l}{ Test block strength calculation } \\
& source & \\
& Y.C. Wei & Z.W. Yang \\
\hline 6 & 27.62448 & 30.05481024 \\
25 & 26.0364 & 27.0476544 \\
50 & 20.8728 & 23.0908704 \\
75 & 15.7092 & 19.1340864 \\
100 & 10.5456 & 15.1773024 \\
\hline
\end{tabular}

Table 3 Comparison of concrete strength calculation on C50

\begin{tabular}{ccc}
\hline & \multicolumn{2}{l}{ Test block strengthcalculation } \\
$\begin{array}{l}\text { The freeze-thaw } \\
\text { cycle times }\end{array}$ & source & \\
& J.P. Zhu & Z.W. Yang \\
\hline 2 & 50.95576873 & 50.32028022 \\
25 & 48.66489736 & 44.35121792 \\
50 & 46.29148231 & 37.86310672 \\
75 & 44.03382007 & 31.37499552 \\
100 & 41.88626533 & 24.88688432 \\
125 & 39.84344806 & 18.39877312 \\
\hline
\end{tabular}

By comparison of Table 1 and Table 2 can be seen: The strength of concrete C30 under the condition of the initial freezing effect for 90 days is equivalent to Yang Zhongwei's computational model of freeze-thaw cycles for 6 times and 5o times when the initial freezing effect for 120 days.

By comparison of Table 1 and Table 3 can be seen: The strength of concrete C50 under the condition of the initial freezing effect in the early 90 days is equivalent to Yang Zhongwei's computational model of freeze-thaw cycles for 2 times and 25 times when the initial freezing effect for 120 days.

\section{The Conclusion}

(1) By the comparative test of normal concrete beams with high-strength concrete beam, obtained that initial freezing effect has some influence on the reinforced concrete beam and the limit load is most prominent. The yield load of C50 beam in normal maintenance and in the initial freezing for 90 days is lower than that of the $\mathrm{C} 30$, but the yield load of beam is larger than $\mathrm{C} 30$ in the initial freezing for 120 days. The ultimate load value in the initial freezing for 120 days was significantly lower than that for 90 days and the two substantially parallel to a line that changes both basically the same .

(2) Under the same load, the bending performance of C50 reinforced concrete beams is higher than that of $\mathrm{C} 30$ in the initial freezing effect for 90 days, but the bending performance of the two kinds of beams are basically the same after the initial freezing for 120 days.

\section{Reference}

[1] CHANA P S. Some Aspects of Modeling the Behaviour of Reinforced Concrete Under Shear Loading[R]. London: Cement and Concrete Association, 1981 
[2]Yang Zhongwei. The experimental Research on the performance of concrete under uniaxialcompression with freeze-thaw cycles [D]. Yangzhou: Master's degree thesis of Yangzhou University, 2010.

[3]Wei Yanchao. Concrete beam calculation model and the later performance prediction research under freeze-thaw cycles [D]. Harbin: Master's degree thesis of Harbin Institute of Technology, 2010.

[4] Zhu Jinpeng.Experimental research on mechanical properties of concrete after freeze-thaw cycle [D].Shandong: Master's degree thesis of Shandong University, 2009.

[5] BresmeF,Camara L G. Computer simulation studies ofCrystallization under confinement condition [J]. ChemicalGeology, 2006, 230:197-206. 
International Forum on Energy, Environment Science and Materials (IFEESM 2015) 